\title{
Analysis of the Human Salivary Peptidome by Differential Peptide Display and LC-MS/MS Overview Sequencing
}

\author{
N. Le Yondre*, H. Tammen, R. Hess, P. Budde and M. Jürgens
}

Digilab BioVisioN GmbH, Feodor-Lynen-Str 5, 30625 Hannover, Germany

\begin{abstract}
In recent years interest in the characterization of the human salivary proteome has increased in order to explore its diagnostic potential. Major constituents of human saliva are highly polymorphic proteins that may have biological roles in oral lubrication and protection, e.g. proline-rich proteins (PRPs), statherins, histatins and cystatins. Interestingly, many of theses proteins are rapidly degraded in the oral cavity by host- and bacteria- or viral-derived proteases. Thus, comprehensive analysis of peptides up to $15 \mathrm{kDa}$ (peptidomics) of whole saliva may yield basic information on proteolytic patterns. By employing a LC-ESI-MS/MS approach a total of 107 native peptides from 17 distinct protein precursors was identified from whole saliva. Subsequently the catalog of peptides was used to analyze inter-individual differences in saliva samples from four donors by differential peptide display technology. Genetic polymorphisms were found in peptides from the PRB4M_HUMAN and PROL4_HUMAN precursors. Analysis of the proposed N- and C-termini of the peptides revealed frequent cleavage after Lys or Arg which is characteristic for salivary kallikrein enzymes. Furthermore, we highlight the cleavage motif Gln/Gly in the PRP-C precursor, which suggests a new proteolytic pattern in saliva.
\end{abstract}

Key Words: Differential peptide display, peptidomics, proteomics, saliva, mass spectrometry.

\section{INTRODUCTION}

Saliva is an important biological fluid for the maintenance and the homeostasis of the oral cavity $[1,2]$. Salivary glands produce an impressive amount of 1,000-2,000 mL/ day. Saliva lubricates and cleans the oral cavity, facilitates speech, aids taste, mastication and swallowing and starts digestion of starches. Saliva forms the first line of oral cavity defense against bacterial and viral attack. In addition to its physiological functions, saliva offers opportunities for the discovery of biomarkers for monitoring general health and early diagnosis of diseases. Recent investigations [3, 4] show the actual growing interest in saliva as a diagnostic fluid due to its relatively simple and minimal invasive collection. Since the concentration of some analytes in saliva and blood are positively correlated, saliva has the potential to serve as a diagnostic specimen [5]. Saliva is also easy to store and transport and in contrast to blood there are minimal collection-associated risks. The search of dynamic marker for rheumatic disease like Sjögren's syndrome [6] found with the proteome of whole saliva an interesting field of action [79]. The proteome of saliva has been investigated by numerous researchers over the last decades and around 1400 distinct precursor proteins were identified [10]. A complete review was recently published on saliva proteome and its polymorphisms [11]. The most abundant identified proteins are proline-rich-proteins (PRPs; $60 \%$ ), $\alpha$-amylase and cystatins $(20 \%)$. The last group consists mainly of histatins, mucins and statherins [12]. Salivary proteins are mainly secreted by the parotid, submandibular and sublingual glands,

*Address correspondence to this author at the Digilab BioVisioN GmbH, Feodor-Lynen-Str 5, 30625 Hannover, Germany;

E-mail: n.leyondre@peptidomics.com but microorganisms, blood and mucosal tissue also contribute to its composition [13, 14]. However, the low-molecular weight proteome or peptidome of saliva is also attracting a rising interest $[15,16]$. Peptides are formed in vivo as processing and degradation products of proteins. Since peptides appear at the end of metabolic pathways, they are likely to include genetic changes as well as changes in protein expression, protein half-life, biochemical and pathobiological pathways. The information value of peptides is considered to be equivalent or even higher than that of genes or proteins in terms of reflecting different health states, simply because peptides exhibit such an enormous diversity [17].

In this study we aimed to characterize the peptidome of saliva by a LC-ESI-MS/MS overview approach. Then in order to reveal interindividual differences (e.g. genetic polymorphisms), the saliva of four healthy individuals was analyzed by Differential Peptide Display ${ }^{\circledR}$ (DPD) [18-21]. DPD is an offline-coupled combination of Reversed-PhaseHPLC and MALDI-TOF mass spectrometry in combination with an in-house developed data display and analysis tools to reveal differences between individual peptidomes. The peptides of interest were subsequently identified by directed approach using additional mass spectrometric methods (offline- or online-coupled LC-ESI-MS/MS as well as MALDITOFTOF-MS/MS) [22, 23].

\section{MATERIALS AND METHODOLOGY}

\section{Sample Collection and Protein Depletion}

Whole saliva was collected from four male healthy nonsmoking donors at four time points using a pre-chilled syringe and all subjects gave informed consent prior to sampling. Proteins were depleted over night with $80 \%$ chilled- 
ethanol (v/v) at $-20^{\circ} \mathrm{C}$ [24]. Subsequently, the samples were centrifuged at $20.000 \mathrm{x}$ g for $30 \mathrm{~min}$ at $4{ }^{\circ} \mathrm{C}$ and the residual protein concentration in the supernatant was determined using the Bradford assay (BCA Protein Assay Kit, Pierce, Rockford, IL).

\section{Differential Peptide Display}

Peptide extracts, with a concentration of $40 \mu \mathrm{g} / \mathrm{mL}$ and representing $145 \mu \mathrm{L}$ saliva equivalent, were processed via the Agilent 1100 chromatography system. After separation on a RP-HPLC column (Source RPC5, 4.6 x 150 mm; Amersham Biosciences Europe GmbH, Freiburg, Germany) by employing an acetonitrile gradient ( $4 \%$ to $40 \%$ in $48 \mathrm{~min}$ ) at a flow rate of $500 \mu \mathrm{l} / \mathrm{min}$ and collection of 96 fractions $(250$ $\mu \mathrm{L}$ each), an equivalent of $5.8 \mu \mathrm{L}$ saliva dissolved in $0.6 \mu \mathrm{L}$ matrix was subjected to MALDI-TOF-MS. The MALDI matrix consisted of alpha-cyano-4-hydroxycinnamic acid (matrix) and 6-deoxy-l-galactose (co-matrix) in acetonitrile containing $0.1 \%$ TFA. Calibration of sample measurements was externally performed. For quality control purposes, each fraction was spiked with a standard peptide (Angiotensin synthetic peptide, $\mathrm{m} / \mathrm{z}=1296 ; 150 \mathrm{fmol}$, Bachem INC, Ca, USA) within the matrix prior to resolubilization of lyophilized fractions. Sample ionization was performed by application of repeated single laser shots over a representative area of the sample spot. The accelerated ions were analyzed in a time-of-flight (TOF) mass spectrometer (4700 Proteomic Analyzer, Applied Biosystems, Framingham, MA, USA).

\section{Data Analysis}

After MS-data acquisition, spectra were analyzed, including peak recognition and visualization using the software package Spectromania ${ }^{\circledR}$ [25]. Quantification of mass spectrometric signals was performed after baseline correction by integrating absolute signal intensities in $1 \mathrm{Da}$ bins. Using the Spectromania ${ }^{\circledR}$ software package, the mass spectrum of each fraction was transformed to a virtual lane. The molecular weight of each peptide is indicated by its position within the virtual lane, whereas the MALDI-TOF-MS signal intensity for each peptide is depicted by the color intensity of the corresponding bar. The converted mass spectra of all 96 fractions were combined, resulting in a two-dimensional display of peptide masses termed peptide display. To reveal differences between individuals comparison of mean displays of all 4 points of each donor respectively correlation analyses were performed.

\section{LC-ESI-MS/MS}

The peptide extract was resuspended in $3.4 \mathrm{~mL}$ water as stock solution. $50 \mu \mathrm{l}$ of the stock solution were diluted with $100 \mu \mathrm{L}$ Water/Formic Acid (99.9/0.1 v/v) and transferred into an HPLC-vial (Waters). The samples (either 10 or 20 $\mu \mathrm{L}$ ) were loaded on a precolumn (Waters Symmetry $300^{\mathrm{TM}}$ ) from a CAPLC XE pump Autosampler (Waters, Milford, MA), using a partial or full loop injection. Peptides were separated on a C18 capillary column (Waters Nanoease Symmetry $300^{\mathrm{TM}} \mathrm{C} 183.5 \mu \mathrm{m} 75 \mu \mathrm{m}$ i.d. x $150 \mathrm{~mm}$ column). A linear gradient from $5 \%$ ACN with $0.1 \%$ formic acid to $41 \%$ ACN was applied for $140 \mathrm{~min}$, and then ramped to 95 $\%$ ACN in $10 \mathrm{~min}$. The resolved peptides were analyzed on a Q-TOF Ultima (Waters, Milford, MA) with the Nano-Spray option (stainless steel tube $0.07 \mathrm{~mm} * 0.03 \mathrm{~mm} * 57 \mathrm{~mm}$, Mecc Technica, co. Hyogo, Japan) and a Nano-ESI source. The capillary voltage and the source temperature were set at 3.2 $\mathrm{kV}$ and $90{ }^{\circ} \mathrm{C}$ respectively. The $\mathrm{m} / \mathrm{z}$ range was set from 300 to 1500 Dalton.

The peptides were chosen using a data depending acquisition (DDA) with a dynamic exclusion of $3 \mathrm{~min}$, the maximal MS/MS scan time was set to $34 \mathrm{~s}$. The collision energy was monitored by collision energy profiling.

\section{ESI-MS(MS)}

Each lyophilized fraction of interest was resuspended in $20 \mu \mathrm{L}$ methanol/water/formic acid (50/49.9/0.1 v/v/v). $3 \mu \mathrm{L}$ was transferred into a Nanoelectrospray capillary (PROXEON, ES380) and analyzed on a Q-TOF Ultima (Waters, Milford, MA) with Nano-ESI source. The capillary voltage and the source temperature were set at $1.3-1.5 \mathrm{kV}$ and $90{ }^{\circ} \mathrm{C}$ respectively. The collision energy and the acquisition time were manually monitored.

\section{Data Processing and Analysis}

MS-MS spectra deconvolutions were either automatically done by Mascot Distiller (MASCOT, Matrix Science, London, UK) or manually with the MassLynx software (Waters, Milford, MA, USA). The datasets were compared with Mascot Search Engine at least against UniProt (Version 54.3 or higher; GeneBio, Geneva, Switzerland) and MSDB (last release 20060831x; EBI, www.ebi.ac.uk) with common posttranslational modification and a peptide and MS-MS tolerance of $0.2 \mathrm{Da}$.

\section{RESULTS}

\section{Overview Approach}

The first objective was a survey characterization of the peptidome of human saliva by LC-MS-MS sequencing. To achieve a good overall coverage of peptides a long-time LC gradient was applied. A first LC-MS-MS run with a dynamic exclusion of $3 \mathrm{~min}$ was performed within $165 \mathrm{~min}$. Afterwards two LC-MS-MS runs with an exclusion list containing already sequenced peptides were performed. The total ion count (TIC) chromatograms are as complex as expected. In Fig. (1), tags indicate regions, where peptides from major proteins are located according to the sequencing results. Main contributors are PRPs, statherin, poly immunoglobulin receptor and Histatine.

\section{Differential Peptide Display}

$\mathrm{DPD}^{\circledR}$ analysis was applied to detect inter-individual perpetual differences. Therefore samples from 4 individuals were collected and peptide displays were generated. In a mean peptide display from human saliva (Fig. 2), between 3000 and 4500 mass spectrometric signals are shown, which corresponds to 1000-1500 individual peptides. This usually reflects redundancy (peptides that elute in more than one fraction), multiple-charge states, peptide species with and without oxidative states, and a small number of mass spectrometric derivatives, such as fragment ions.

The coefficient of variation (CV) of the MS signal intensity of the synthetic peptide angiotensin was calculated for 


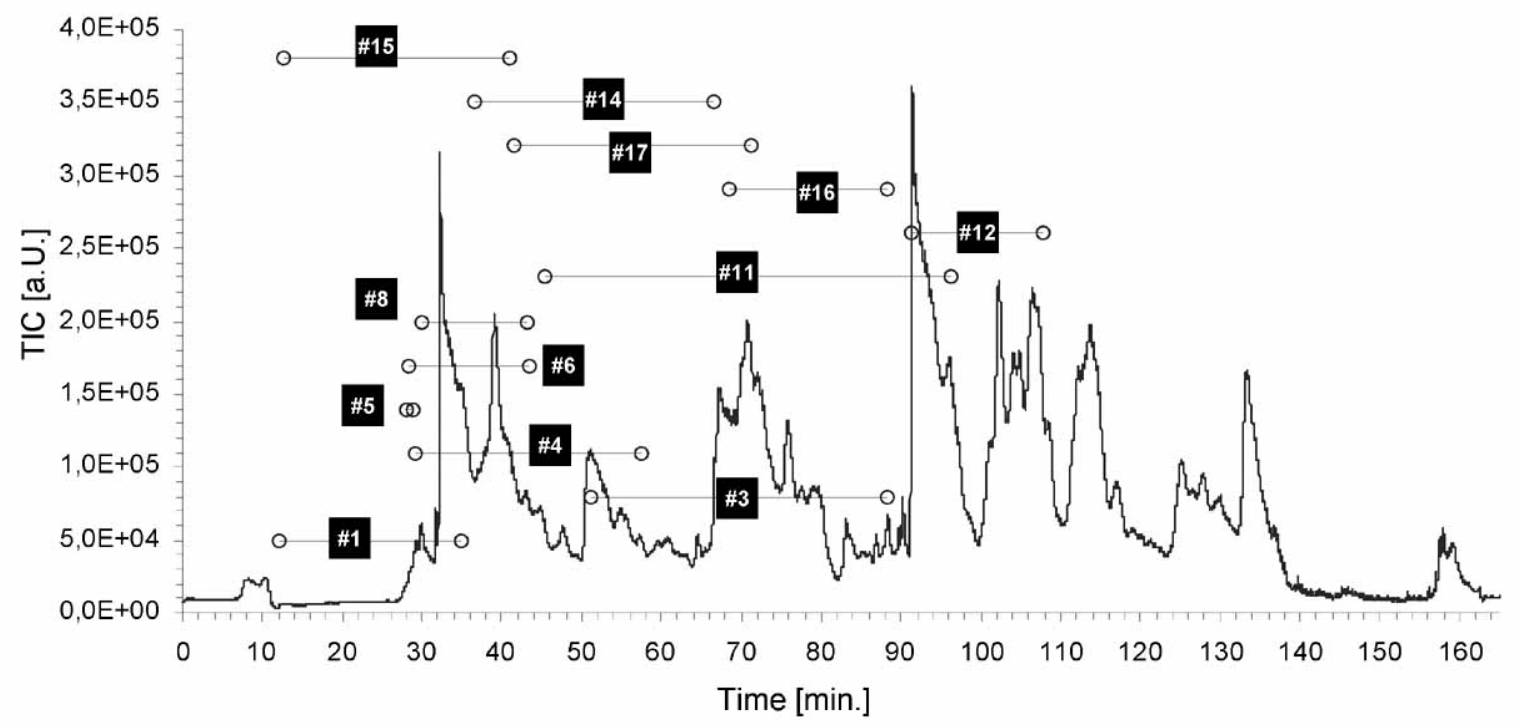

Fig. (1). Annotated LC-MS chromatogram of whole saliva.

The figure shows an HPLC-ESI-MS total ion count (TIC) profile of whole saliva. The elution range delimitated by LC/MS-MS identifications are annotated: PRP-Acidic (PRPC_HUMAN \#1), PRP-Basic (PRP1_HUMAN \#3, PRP5_HUMAN \#4, PRPE_HUMAN \#5, PRB2_HUMAN \#6 and PRB4M_HUMAN \#8), PRP-other (PROL3_HUMAN \#11 and PROL4_HUMAN \#12), Statherin (STAT_HUMAN \#16), Poly-Ig Receptor (PIGR_HUMAN \#17) and Histatine (HIS1_HUMAN \#14 and HIS3_HUMAN \#15).

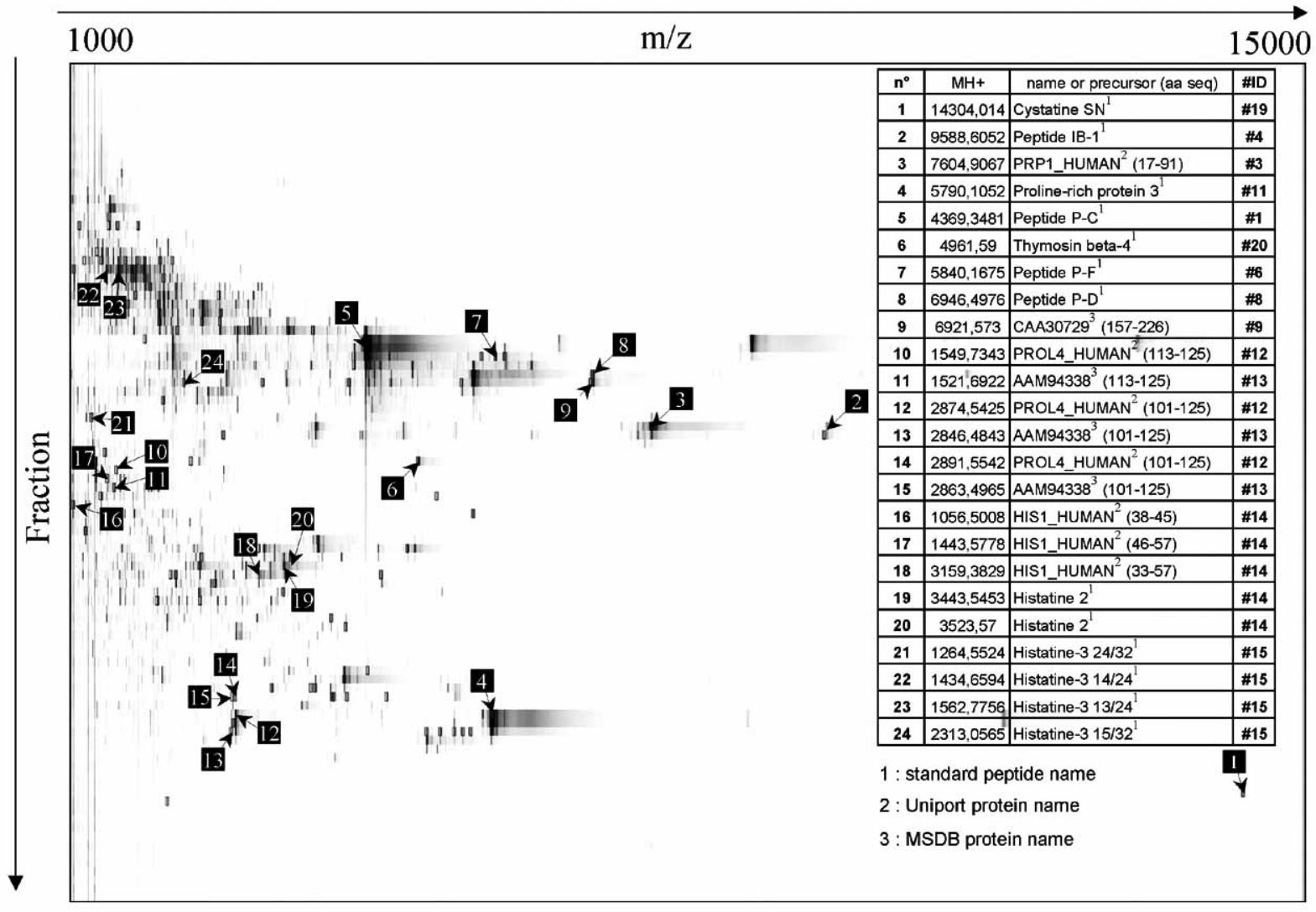

Fig. (2). Mean peptide display of human saliva.

The figure shows a mean peptide display of human saliva. The y-axis represents the hydrophobicity and the x-axis the molecular mass. The intensity of MS-signals is depicted by the color saturation. Sequenced peptides are surrounded by a square and major components are annotated (The numerals refer to the inserted table). The inserted table contains index number, the molecular mass, the precursor name and precursor ID. 
each fraction in all samples and its distribution is depicted in Fig. (3). The median CV of angiotensin was $40 \%$. The bimodal distribution is related to high mass spectrometric signals in the fraction range between fraction 32 and 38 (compare to Fig. 2), which was identified as the Peptide P-C (peptide 1.09 see Supplement table /PRPC_HUMAN_123-166, $\mathrm{MH}^{+}$4369.35). This high abundant peptide influences the mass spectrometric measurement in terms of signal compression.

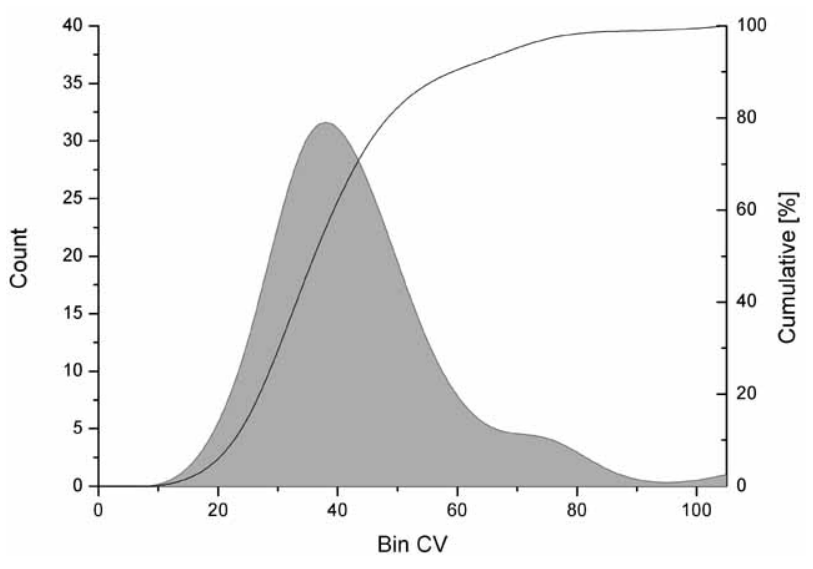

Fig. (3). Distribution of variance.

The histogram depicts the distribution of the coefficient of variation (CV) of the spiked standard angiotensin. The line graph represents the cumulative counts. The bimodal distribution is related to signal suppression in a distinct region of the displays (see text for details).

The displays of all 4 points of each donor were compared by correlation analysis [26]. This analysis revealed several signals, which allow for discrimination between individuals (Fig. 4).

\section{Directed Approach}

After identification or confirmation for each person, the signals with molecular masses of 6946.50 respectively 6920.57 were identified as the Peptide P-D (peptide 8.04/ PRB4M_HUMAN_169_238) and a variant peptide (peptide 9.01) with an amino acid exchange (Alanine to Proline) in position 200. Signals with molecular masses of 2874.54 and 2846.48 are truncated or modified forms of the fragment of Proline-rich protein 4 (peptide 12.03/ PROL4_HUMAN_ 113-125) and a variant peptide (peptide 13.03) with an amino acid exchange (Arginine to Glutamine) in position 120.

\section{DISCUSSION}

\section{Ions Precursor Description}

For this study, approximately 1600 precursor ions were analyzed leading to 210 identifications, which correspond to 107 non-redundant peptides (Supplement Table 1). For the 107 precursor ions, generally the charge states were $2+, 3+$ or $4+(74 \%)$, the $\mathrm{m} / \mathrm{z}$ was uniformly distributed on a range between 500 and $1100 \mathrm{Da}(90 \%)$ and the $\mathrm{mH}+$ comprised between 1000 and $3000 \mathrm{Da}(58 \%)$.

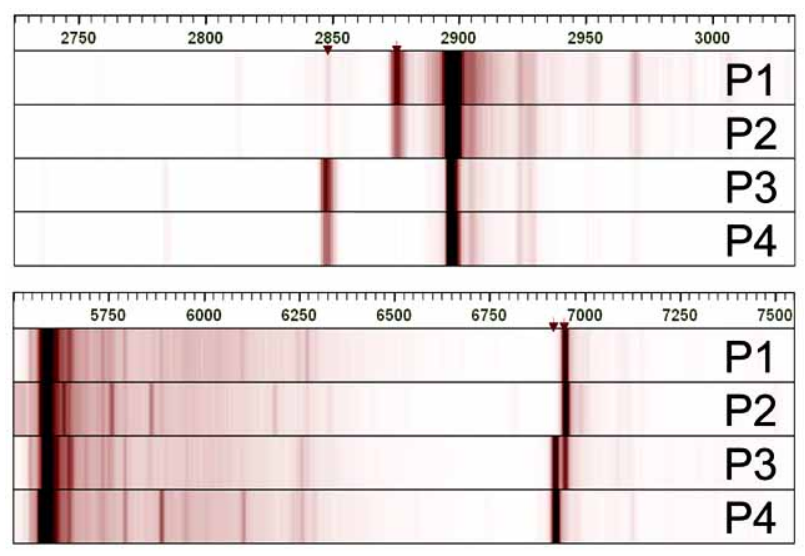

Fig. (4). Lane views of distinct regions of individual peptide displays.

Each lane represents a distinct region (molecular mass and hydrophobicity) of individual (P1-P4) peptide displays. Differentiating signals are marked by arrows. (Upper panel) The peptides with masses of 2846.48 and 2874.54 were identified as fragments of Proline-rich protein 4 (PROL4_HUMAN respectively AAM94338) with an amino acid exchange (Arginine to Glutamine) in position 120. (Lower panel) The masses of $6920.57 \mathrm{Da}$ and $6946.75 \mathrm{Da}$ were identified as peptides deriving from basic salivary proline-rich protein 4 (PRB4M_HUMAN respectively CAA30729) with an amino acid exchange in position 200 (Alanine to Proline). P1, P2, $\mathrm{P} 4$ are homozygous and P3 is heterozygous at this locus.

\section{Protein Precursor Composition}

The composition is in accordance with previously published results [15]. For the best of our knowledge, around 70 peptide sequences are novel. Nearly $70 \%$ are represented by the Proline-rich protein family (PRPs) and spread onto 13 different precursors (Fig. 5).

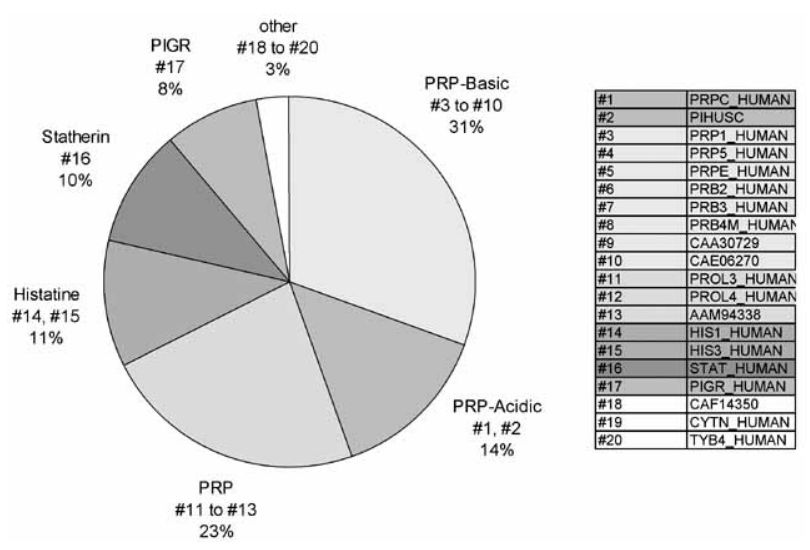

Fig. (5). Identified precursor proteins.

The pie graph illustrates the precursor composition of all identifications (overview and directed approach). The main fraction consists of Proline Rich Proteins, followed by Histatine, Statherin and Poly-Ig Receptor. This distribution is in accordance to previous publications.

$11 \%$ of sequences are either from Histatine 1 or 3 . Histatine 3 has been well described and sequenced [16, 27]. We 
additionally sequenced 3 new peptides derived from Histatine 1 HIS1_HUMAN (_38-45,_33-57 and _31-57, $\mathrm{MH}^{+}$: $1056.5,3159.38$ and 3523.53). The latter is Histatine 2 with a tyrosine sulfation, this post-translational modification was attributed according to the HPLC shift and confirmed recently [28].

Furthermore peptides derived from Statherin, Thymosinbeta-4 and Poly-IG-Receptor precursor were also identified, the latter two potentially derived from the mucosal tissue of the oral cavity.

\section{Pyrrolidone Carboxylic Acid}

Within the 27 peptides with a post-translational modification, two third were cleavage products of PROL3_HUMAN [29], PROL4_HUMAN [30] or AAM94338 [31] and bearing at least the pyrrolidone carboxylic acid (Q) modification.

\section{Polymorphisms}

\section{PROL4_HUMAN}

3 couples of peptides were identified as fragments of Proline-rich protein $4[30,31]$ with an amino acid exchange (Arginine to Glutamine) in position 120. This amino acid exchange was detectable in following fragments: PROL4_ HUMAN (_113-125, _101-125, _101-125, $\mathrm{MH}^{+}$: 1549.73, 2874.54, 2891.55) and AAM94338 (_113-125, _101-125, 101-125, $\left.\mathrm{MH}^{+}: 1521.69,2846.48,2863.49\right) . \mathrm{P} 1, \mathrm{P} 2$ are homozygous at the first locus and P3, P4 are also homozygous at the second locus. (Fig. 4 upper panel)

\section{PRB4M_HUMAN}

The molecular masses of $6946.75 \mathrm{Da}$ and $6920.57 \mathrm{Da}$ were identified as peptides deriving from Basic Salivary Proline-Rich Protein $4[32,33]$. The $\mathrm{m} / \mathrm{z}$ shift of $26 \mathrm{Da}$ is due to an amino acid exchange in position 200 (Alanine to Proline). P1, P2, P4 are homozygous and P3 is heterozygous at this locus. (Fig. 4 lower panel)

\section{Cleavage Site}

The analysis of $\mathrm{N}$ - and $\mathrm{C}$-terminal regions of sequenced peptides (Fig. 6) revealed that 37 peptides result from cleavage before or after Arginine, which is most likely related to the kallikrein family [34-36], which has a wide tissue distribution including the salivary glands.

Interestingly 44 of 107 distinct peptides, all corresponding to PRPs, consist of Q-G cleavage sites. At least 2 plausible peptidase families exist according to Merops database [37]. On the one hand the cleavage motif could correspond to bacterial proteases or on the other hand to cathepsins. Cathepsins are known to process Collagens, which possess a high structural homology to PRP's. Nevertheless it is conceivable that an interplay between human exo- and endopeptidases could mimic this cleavage specificity.

In Fig. (7), the identified peptides of PRPC_HUMAN [38] are aligned with the original sequence and the potential QG cleavage are underlined.

\section{Polymeric Immunoglobulin Receptor}

The eight non-redundant peptide sequences from PIGR_HUMAN span an unstructured region that links the
Ig-like domain $\mathrm{V}$ to the transmembrane region and a short part of the transmembrane region (Fig. 8). The mechanism by which $\mathrm{pIgR}$ is cleaved to secretory component and the precise cleavage site are currently unknown. Studies using free secretory component purified from colostrums showed that processing can occur on multiple cleavage sites and is likely to be cell-type specific [39].

$\mathrm{N}$-terminal cleavage

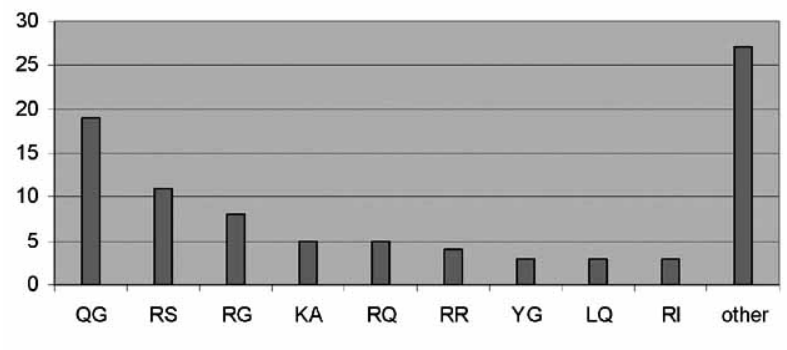

C-terminal cleavage

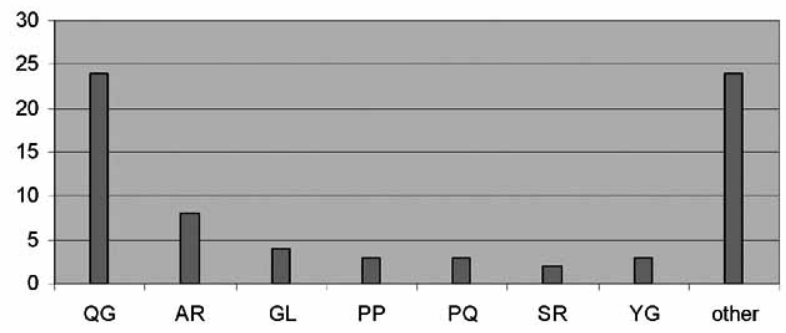

Fig. (6) Frequency of $\mathrm{N}$ - and $\mathrm{C}$-terminal cleavage motifs.

The column graph shows the frequency of $\mathrm{N}$ - and $\mathrm{C}$-terminal motifs in all peptides identified. The most frequent motifs are Q-G (44 times) and the R-X (37 times).

\section{CONCLUSION}

The characterization of the saliva peptidome confirmed previously published results, but also delivered new insights in the peptide composition of human saliva.

The differential analysis demonstrated that a mass spectrometric comparison of human saliva allow for distinguishing individuals.

Since native peptides encode the processing of the preceding molecule an analysis of terminal amino acid residues was performed. The majority of peptides could be assigned to presumptive proteases. Additionally a new cleavage motif in PRP's was identified, which might be related to micro bacterial proteases. This could indicate a broader biological role of PRP's.

Taken together the human saliva contains a plethora of native peptides, which may contain relevant information for stratification of individuals or disease groups. A comparison of mass spectrometric profiles from human saliva is in principle possible. It may pave the way to develop diagnostic tests for indications like diseases of salivary glands (e.g. adenoid cystic or mucoepidermoid carcinomas).

Further studies will prove if differences in these profiles allow for discovery of diagnostic useful peptidic biomarkers. 


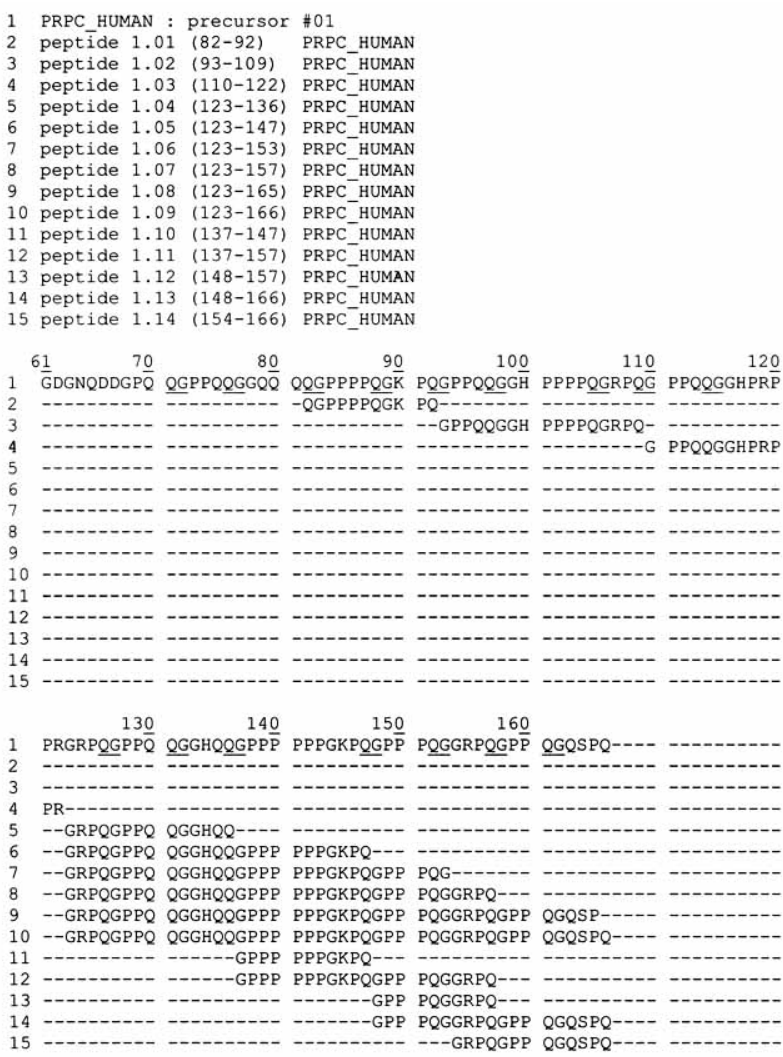

Fig. (7). alignement scheme.

The alignment pattern shows the correspondence between identified peptides and the theoretical sequence of PRPC_HUMAN. The potential QG cleavage are underlined.

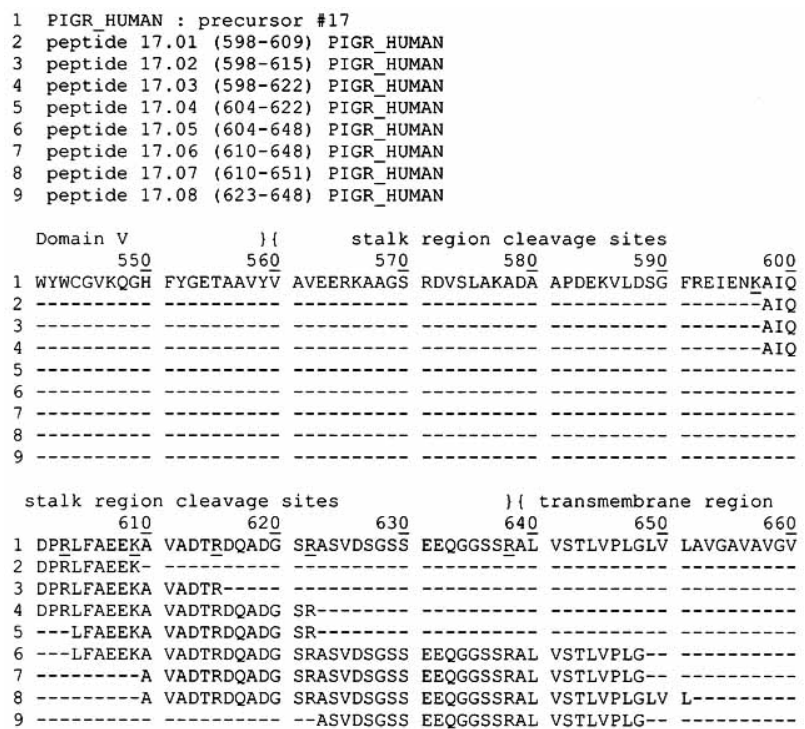

\section{Fig. (8). alignement scheme.}

The alignment pattern shows the correspondence between identified peptides and the theoretical sequence of PIGR_HUMAN. The potential kallikrein-like cleavage site are underlined. Protein parts are annotated (Domain V, stalk region cleavage sites and the transmembrane region).

\section{ACKNOWLEDGEMENT}

We acknowledge the financial support of an EU Marie Curie Industry Host Fellowship (HPMI-CT-2002-00203).

\section{REFERENCES}

[1] Pedersen, A.M.; Bardow, A.; Jensen, S.B.; Nauntofte, B. Saliva and gastrointestinal functions of taste, mastication, swallowing and digestion. Oral Dis., 2002, 8(3), 117-29.

[2] Amerongen, A.V.; Veerman, E.C. Saliva--the defender of the oral cavity. Oral Dis., 2002, 8(1), 12-22.

[3] Hu, S.; Yu, T.; Xie, Y.; Yang, Y.; Li, Y.; Zhou, X.; Tsung, S.; Loo, R.R.; Loo, J.R.; Wong, D.T. Discovery of oral fluid biomarkers for human oral cancer by mass spectrometry. Cancer Genomics Proteomics, 2007, 4(2), 55-64

[4] Hu, S.; Loo, J.A.; Wong, D.T. Human saliva proteome analysis and disease biomarker discovery. Expert Rev. Proteomics, 2007, 4(4), 531-8.

[5] Amado, F.M.; Vitorino, R.M.; Domingues, P.M.; Lobo, M.J.; Duarte, J.A. Analysis of the human saliva proteome. Expert Rev. Proteomics, 2005, 2(4), 521-39.

[6] Pedersen, A.M.; Bardow, A.; Nauntofte, B. Salivary changes and dental caries as potential oral markers of autoimmune salivary gland dysfunction in primary Sjogren's syndrome. BMC Clin. Pathol., 2005, 5(1), 4.

[7] Ryu, O.H.; Atkinson, J.C.; Hoehn, G.T.; Illei, G.G.; Hart, T.C. Identification of parotid salivary biomarkers in Sjogren's syndrome by surface-enhanced laser desorption/ionization time-of-flight mass spectrometry and two-dimensional difference gel electrophoresis. Rheumatology (Oxford), 2006, 45(9), 1077-86.

[8] Giusti, L.; Baldini, C.; Bazzichi, L.; Ciregia, F.; Tonazzini, I.; Mascia, G.; Giannaccini, G.; Bombardieri, S.; Lucacchini, A. Proteome analysis of whole saliva: a new tool for rheumatic diseases-the example of Sjogren's syndrome. Proteomics, 2007, 7(10), 1634 43.

[9] Rigante, D.; Inzitari, R.; Carone, M.; Fanali, C.; Stabile, A.; Cabras, T.; Capoluongo, E.; Gaspari, S.; Barone, G.; Castagnola, M. Correspondence between clinical improvement and proteomic changes of the salivary peptide complex in a child with primary Sjögren syndrome. Rheumatol. Int., 2008, 28(8), 801-6.

[10] Guo, T.; Rudnick, P.A.; Wang, W.; Lee, C.S.; DeVoe, D.L.; Balgley, B.M. Characterization of the human salivary proteome by capillary isoelectric focusing/nanoreversed-phase liquid chromatography coupled with ESI-tandem MS. J. Proteome Res., 2006, 5(6), 1469-78.

[11] Oppenheim, F.G.; Salih, E.; Siqueira, W.L.; Zhang, W. Helmerhorst, E.J. Salivary proteome and its genetic polymorphisms. Ann. N.Y. Acad. Sci., 2007, 1098, 22-50.

[12] Castagnola, M.; Congiu, D.; Denotti, G.; Di Nunzio, A. Determination of the human salivary peptides histatins $1,3,5$ and statherin by high-performance liquid chromatography and by diode-array detection. J. Chromatogr. B. Biomed. Sci. Appl., 2001, 751(1), 153-60.

[13] Macarthur, D.J.; Jacques, N.A. Proteome analysis of oral pathogens. J. Dent. Res., 2003, 82(11), 870-6.

[14] Huang, C.M. Comparative proteomic analysis of human whole saliva. Arch. Oral. Biol., 2004, 49(12), 951-62.

[15] Vitorino, R.; Lobo, M.J.; Duarte, J.A.; Ferrer-Correia, A.J.; Domingues, P.M.; Amado, F.M. Biomed. Chromatogr., 2004, 18(8), 570-5.

[16] Hardt, M.; Thomas, L.R.; Dixon, S.E.; Newport, G.; Agabian, N.; Prakobphol, A.; Hall, S.C.; Witkowska, H.E.; Fisher, S.J. Toward defining the human parotid gland salivary proteome and peptidome: identification and characterization using 2D SDS-PAGE, ultrafiltration, HPLC, and mass spectrometry. Biochemistry, 2005, 44(8), 2885-99.

[17] Schulte, I.; Tammen, H.; Selle, H.; Schulz-Knappe, P. Peptides in body fluids and tissues as markers of disease. Expert Rev. Mol. Diagn., 2005, 5(2), 145-57.

[18] Schulz-Knappe, P.; Zucht, H.D.; Heine, G.; Jürgens, M.; Hess, R.; Schrader, M. Peptidomics: the comprehensive analysis of peptides in complex biological mixtures. Comb. Chem. High Throughput Screen., 2001, 4(2), 207-17.

[19] Tammen, H.; Kreipe, H.; Hess, R.; Kellmann, M.; Lehmann, U.; Pich, A.; Lamping, N.; Schulz-Knappe, P.; Zucht, H.D.; Lilischkis, 
R. Expression profiling of breast cancer cells by differential peptide display. Breast Cancer Res. Treat., 2003, 79(1), 83-93.

[20] Schrader, M.; Schulz-Knappe, P. Peptidomics technologies for human body fluids. Trends. Biotechnol., 2001, $19(10 \mathrm{Suppl}), 55-$ 60.

[21] Tammen, H.; Schulte, I.; Hess, R.; Menzel, C.; Kellmann, M.; Mohring, T.; Schulz-Knappe, P. Peptidomic analysis of human blood specimens: comparison between plasma specimens and serum by differential peptide display. Proteomics, 2005, 5(13), 341422.

[22] Mohring, T.; Kellmann, M.; Jurgens, M.; Schrader, M. Top-down identification of endogenous peptides up to $9 \mathrm{kDa}$ in cerebrospinal fluid and brain tissue by nanoelectrospray quadrupole time-offlight tandem mass spectrometry. J. Mass Spectrom., 2005, 40(2), 214-26.

[23] Menzel, C.; Guillou, V.; Kellmann, M.; Khamenya, V.; Juergens, M.; Schulz-Knappe, P. High-throughput biomarker discovery and identification by mass spectrometry. Comb. Chem. High Throughput Screen., 2005, 8(8), 743-55.

[24] Perinpanayagam, H.E.; Van Wuyckhuyse, B.C.; Ji, Z.S.; Tabak, L.A. Characterization of low-molecular-weight peptides in human parotid saliva. J. Dent. Res., 1995, 74(1), 345-50.

[25] Zucht, H.D.; Lamerz, J.; Khamenia, V.; Schiller, C.; Appel, A.; Tammen, H.; Crameri, R.; Selle, H. Datamining methodology for LC-MALDI-MS based peptide profiling. Comb. Chem. High Throughput Screen., 2005, 8(8), 717-23.

[26] Lamerz, J.; Selle, H.; Scapozza, L.; Crameri, R.; Schulz-Knappe, P.; Mohring, T.; Kellmann, M.; Khamenia, V.; Zucht, H.D. Correlation-associated peptide networks of human cerebrospinal fluid. Proteomics, 2005, 5(11), 2789-98.

[27] Castagnola, M.; Inzitari, R.; Rossetti, D.V.; Olmi, C.; Cabras, T.; Piras, V.; Nicolussi, P.; Sanna, M.T.; Pellegrini, M.; Giardina, B.; Messana, I. A cascade of 24 histatins (histatin 3 fragments) in human saliva. Suggestions for a pre-secretory sequential cleavage pathway. J. Biol. Chem., 2004, 279(40), 41436-43.
[28] Cabras, T.; Fanali, C.; Monteiro, J.A.; Amado, F.; Inzitari, R.; Desiderio, C.; Scarano, E.; Giardina, B.; Castagnola, M.; Messana, I. Tyrosine polysulfation of human salivary histatin 1. A posttranslational modification specific of the submandibular gland. $J$. Proteome Res., 2007, 6(7), 2472-80.

[29] SMR3B_HUMAN (Sprot_human; date of access : October 15, 2007): http://www.expasy.org/uniprot/P02814

[30] PROL4_HUMAN (Sprot_human; date of access : October 15, 2007): http://www.expasy.org/uniprot/Q16378

[31] AAM94338 (MSDB; date of access : October 15, 2007): http:// www.expasy.org/cgi-bin/get-sprot-variant.pl?VAR_027927

[32] PRB4_HUMAN (Sprot_human; date of access : October 15, 2007): http://www.expasy.org/uniprot/P10163

[33] CAA30729 (MSDB; date of access : October 15, 2007): http:// www.expasy.org/cgi-bin/get-sprot-variant.pl?VAR_031551

[34] Kumar, A.; Goel, A.S.; Hill, T.M.; Mikolajczyk, S.D.; Millar, L.S ; Kuus-Reichel, K.; Saedi, M.S. Expression of human glandular kallikrein, hK2, in mammalian cells. Cancer Res., 1996, 56(23), 5397-402.

[35] Diamandis, E.P.; Yousef, G.M.; Olsson, A.Y. An update on human and mouse glandular kallikreins. Clin. Biochem., 2004, 37(4), 25860.

[36] Darling, M.R.; Jackson-Boeters, L.; Daley, T.D.; Diamandis, E.P. J. Histochem. Cytochem., 2006, 54(3), 337-42.

[37] Rawlings ND, Morton FR, Kok CY, Kong J, Barrett AJ. MEROPS the peptidase database. Nucleic Acids Res., 2006, 34, D270-D272.

[38] PRPC_HUMAN (Sprot_human; date of access : October 15, 2007): http://www.expasy.org/uniprot/P02810

[39] Asano, M.; Takenouchi-Ohkubo, N.; Matsumoto, N.; Ogura, Y.; Nomura, H.; Suguro, H.; Moro, I. Multiple cleavage sites for polymeric immunoglobulin receptor. Immunology, 2004, 112(4), 58339.

(C) Le Yondre et al.; Licensee Bentham Open.

This is an open access article licensed under the terms of the Creative Commons Attribution Non-Commercial License (http://creativecommons.org/licenses/ by-nc/3.0/) which permits unrestricted, non-commercial use, distribution and reproduction in any medium, provided the work is properly cited. 